\title{
Perineal xanthogranulomatous pseudotumor due to intermittent catheterization: a liposarcoma mimic. Case report
}

\author{
W D Belville MD ${ }^{1} \mathrm{~J}$ M Park MD ${ }^{2} \mathrm{~J}$ L Kelly MD ${ }^{3} \mathrm{~J}$ A Vaccaro MD ${ }^{4}$ \\ ${ }^{1}$ Associate Professor of Surgery, ${ }^{2}$ Urology Resident, Department of Surgery, Section of \\ Urology, University of Michigan Hospitals, 1500 E Medical Center Drive, Ann Arbor, \\ MI 48109; ${ }^{3}$ Chief of Anatomical Pathology, ${ }^{4}$ Chief of Surgery, Department of Pathology \\ and Urology Service, Madigan Army Medical Center, Tacoma, WA 98431, USA.
}

\begin{abstract}
A large perineal fatty tissue mass shown to be an encapsulated xanthogranulomatous reaction was found in a spinal cord injured man whose neuropathic bladder was for a long time being managed by clean intermittent catheterization, but who had chronic urinary tract infection. He was also known to be a chronic alcoholic. We would say that an alcohol numbed sensorium and multiple catheterizations led to recurrent small urethral perforations which in the setting of chronic bacteriuria promoted the unusual inflammatory mass. Appreciating the increasing use of clean intermittent catheterization for the spinal cord injured, we suspect that similar cases of 'xanthogranulomatous pseudotumors' will be found, and therefore we describe this most unusual clinical presentation.
\end{abstract}

Keywords: perineal xanthogranuloma; catheterization; complication.

\section{Introduction}

The perineum is a unique soft tissue region which lends itself to ease of physical examination. Although primary malignancies of the perineum are rare, any mass found in this region will lead to considerable anxiety. We briefly review perineal masses and add to this list a most unusual mass which we believe to be the first reported case of a perineal xanthogranulomatous pseudotumor.

\section{Case report}

A 62 year old male SCI patient had bladder function maintained by clean intermittent self catheterization (ISC) for the past 7 years. $\mathrm{He}$ had a daily consumption of 6-8 liters of wine, but was in good general health when he presented with a painless perineal mass. This progressively enlarging mass of 4-6 weeks duration was unassociated with fever, weight loss, malaise or hematuria. On examination, a firm midline perineal mass of approximately $3 \times$ $5 \mathrm{~cm}$ was found and it was fixed, noncompressible, and nontender. Subsequent retrograde urethrography, intravenous pyelography, and computed tomography were unremarkable other than revealing a small scarred right kid- ney, compatible with chronic pyelonephritis. Laboratory studies including $\mathrm{CBC}$, electrolytes, creatinine, and BUN were within normal limits. There was a slight abnormality of the liver function tests. Persistent silent chronic bacteriuria ( $>100 \mathrm{~K} \mathrm{E}$. Coli and $>100 \mathrm{~K}$ S. viridans) was again found.

After detoxification and lengthy counselling, surgical exploration was recommended, with a preoperative diagnosis of possible liposarcoma. The perineum was opened through the midline, and a well-encapsulated fatty mass surrounding the bulbar urethra was uneventfully excised (Fig 1).

Histologically the tissue showed a predominance of lipid laden macrophages (foam cells)

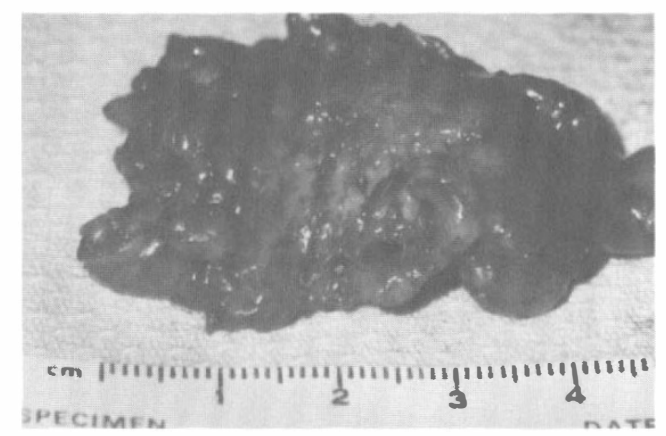

Figure 1 Fibro-fatty perineal mass. 
a

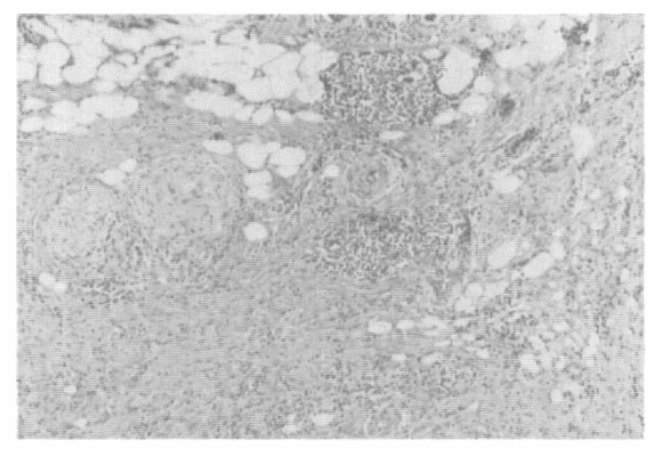

b

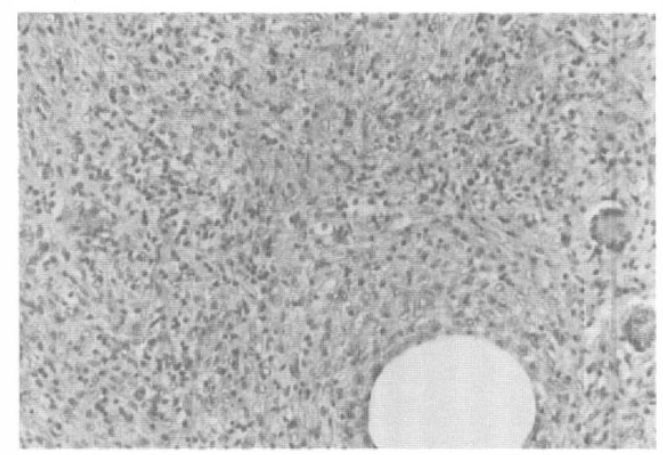

Figure 2 (a) Low power view of perineal mass. Note the fat and inflammatory cells. (b) High power magnification showing foam cells, lymphocytes, giant cells, plasma cells, and fat.

along with fibroblasts, lymphocytes, plasma cells, giant cells, and fat consistent with the diagnosis of xanthogranuloma (Fig 2). On follow up examination 6 months later, there was no evidence of recurrence. He had remained alcohol free during this interval.

\section{Discussion}

It is rare to find a nontender mass in the perineum and therefore finding one generated considerable anxiety.

Although there are many reports of perineal masses, most have been sporadic case reports. Neoplasms of the extraperitoneal rectum and anus may present as a palpable mass in the perineum, but are rare. Mangiante et al reported a series of 120 patients with biopsy-proven neoplasms of anorectal origin, but none presented as a perineal mass. ${ }^{1}$ Perianal or anal margin carcinomas arising outside the anal verge have the same potential pathology as other skin malignancies, such as squamous cell carcinoma and melanoma. Their initial presentation as a perineal mass is also rare. ${ }^{2}$ Gritsch et al reported the case of a giant condylomata acuminata of the perineum, but such occurrence is unusual and this diagnosis is easily made by the characteristic exophytic appearance. ${ }^{3}$ A number of cystic structures may present as a perineal mass, including ectopic ureterocele, ${ }^{4}$ dilatation of Cowper's gland duct, ${ }^{5}$ urethroperineal cyst from a posterior urethral duplication, ${ }^{6}$ and a clo- acogenic cyst. ${ }^{7}$ These are also case reports, and are of rare occurrence. Liposarcomas, being the most common of the soft tissue sarcomas, have also been reported in the perineum. ${ }^{8}$ Steeper et al reported a series of nine patients with angiomyxoma, two of whom presented as a perineal mass. ${ }^{9}$ Other reported rare entities include periurethral neurofibroma, ${ }^{10}$ granular cell tumor ${ }^{11}$ and perineal infiltration by plasma cells in an individual with multiple myeloma. ${ }^{12}$

We were unable to find any previous report of a perineal mass secondary to a xanthogranulomatous reaction. Xanthogranulomatous pyelonephritis (XGP) is a well established pathological entity, but search of the literature fails to show any other similar case. XGP is a chronic form of pyelonephritis, usually associated with calculi or obstruction, and often with a clinical presentation suggestive of a renal mass. The typical histological appearance is characterized by a cellular infiltrate of lipid laden mononuclear macrophages (foam cells) in the diffuse background of adipose and fibrous tissue very similar to the histological findings seen in our patient.

The exact etiology of XGP is unknown. Venous occlusion, hemorrhage, lymphatic obstruction, prolonged antibiotic therapy with chronic renal obstruction and infection, altered immune status, impaired cellular immune response, abnormal lipid metabolism, renal ischemia, diabetes and malignancy have all been suggested as contributing to a xanthogranulomatous inflammatory 
response. Organisms frequently implicated in XGP are E. coli and P. mirabilis, and the calculi are usually composed of struvite. ${ }^{13}$

In this report, we suggest that the xanthogranulomatous inflammatory reaction was the result of recurrent trauma to the urethra from chronic ISC in the setting of numbed sensorium and a state of high urine output requiring multiple catheterizations. The presence of chronic bacteriuria was also likely to be a contributing factor. Since ISC is being used increasingly in SCI patients, we suggest that similar cases will probably be identified. Hopefully, with a preoperative diagnosis of possible perineal xanthogranulomatous pseudotumor the serious anxiety associated with a potential liposarcoma will be alleviated.

\section{References}

1 Mangiante EC, Dilawari RA, Britt LG (1983) Neoplasia of the extraperitoneal rectum and anus. Am Surg 49: 73-75.

2 Waugh DE (1986) Anal and perianal malignancies. Surg Clin North Am 66: 841-844.

3 Gritsch HA, Randazzo RF, Layfield LJ, DeKernion JB (1989) Invasive giant condylomata acuminata: A case report. J Urol 141: 950-952.

4 Rocereto TF, Campbell WA III (1980) Ureterocele presenting as a perineal cyst. Obstet Gynecol 55: 54-56.

5 Redman JF, Rountree GA (1988). Pronounced dilatation of Cowper's gland duct manifest as a perineal mass: A recommendation for management. J Urol 139: 87-88.

6 Anderson RL, Altman DH, Lankau CA, Lopez P (1980) Urethroperineal cyst in a newborn: Posterior urethral duplication. AJR 135: 622-624.

7 Anani P, Leu F, Delacrétaz J (1983) Perineal cloacogenic cyst. Dermatologica 166: 104-106.

8 Hulbert JC, Rodriguez PN, Cummings KB (1984) Perineal liposarcoma: Diagnosis and management. J Urol 131: $1185-1187$.

9 Steeper TA, Rosai J (1983) Aggresive angiomyxoma of the female pelvis and perineum. Am J Surg Pathol 7: 463-475.

10 Selli C, Villari D, Amorosi A et al (1987) Periurethral neurofibroma. Urology 30: 82-83.

11 Hansborg N, Refn H (1981) Granular cell tumor in the perineum. Acta Obstet Gynecol Scand 60: $219-221$.

12 Lewinski UH, Bayer I, Turani H (1984) Perineal infiltration by plasma cells in a patient with multiple myeloma. Dis Colon Rectum 27: 479-480.

13 Petronic V, Buturovic J, Isvaneski M (1989) Xanthogranulomatous pyelonephritis. Br J Urol 64: 336-338. 